\title{
Research on the New Media Communication of NetEase Games*
}

\author{
Lu Wang \\ College of Arts and Sciences \\ Shanghai Polytechnic University \\ Shanghai, China 201209
}

\author{
Xiaozhuo Jiang \\ College of Arts and Sciences \\ Shanghai Polytechnic University \\ Shanghai, China 201209
}

\begin{abstract}
At present, online games and new media are in the rising period of social development. People are making contacts with them all the time in their daily life directly or indirectly, actively or passively. NetEase games has shown its own communication capabilities and promotion potential in the field of new media communication and achieved a certain degree of communication results, but it also reflects many problems in the new media communication. Making in-depth analysis by combining with the new media communication, exploring how to better jump out of the strange circle of generalized and stereotypical new media communication of game companies and break the social public's immunity to the communication mode become the problems that need to be solved urgently for the new media communication of NetEase games.
\end{abstract}

Keywords—new media communication; NetEase games

\section{INTRODUCTION}

Nowadays, online games and new media are in the rising period of social development and people can contacts with them every hour and moment in their daily life directly or indirectly, actively or passively. The seamless connection between new media and people's lives has led more and more online game companies to shift their energies to the new media communication and promotion, popularization and marketing of their games and the company. NetEase games has shown its own communication capabilities and promotion potential in the field of new media communication and achieved a certain degree of communication results. It also exposes many problems in the new media communication. How to better jump out of the strange circle of generalized and stereotypical new media communication of game companies and break the social public's immunity to the communication mode become the problems that need to be solved urgently for the new media communication of NetEase games.

\section{The Status Quo of NeW Media Communication of NeTEASE GAME}

\section{A. Introduction to NetEase Game}

NetEase Game is an online game department formally established by NetEase in 2001, which has nearly 20 years of development process. The brand value of NetEase games has now exceeded US\$1.3 billion, becoming one of the seven largest game companies in the world. In China, NetEase Game is a leading player in game development and an independent leader in online game development. In December 2016, NetEase Games was appraised as "2016 Top Ten Chinese Branded Game Company".

In recent years, the mobile game market has begun to develop strongly in China. NetEase games have also gradually strengthened the R\&D efforts for mobile game in China. From 2016 to 2018, NetEase mobile game has reached the eruption period when a variety of mobile game with high quality are put forward and it keeps a record of millions of game players online at the same time.

\section{B. Current Market of NetEase Game}

According to statistics in "Fig. 1", the Chinese game market in 2017 is still growing at a high speed. The actual sales revenue has exceeded 99.78 billion yuan, and the number of game users in China has reached 507 million in the same period of last year. The growth rate continues to decline, and the scale of users tends to be stable.

*This paper is the research achievement of the "New Media Public Relations Communication" (subject number: XXKPY 1610) of the Public Relations Discipline Construction Project of Shanghai Polytechnic University. 


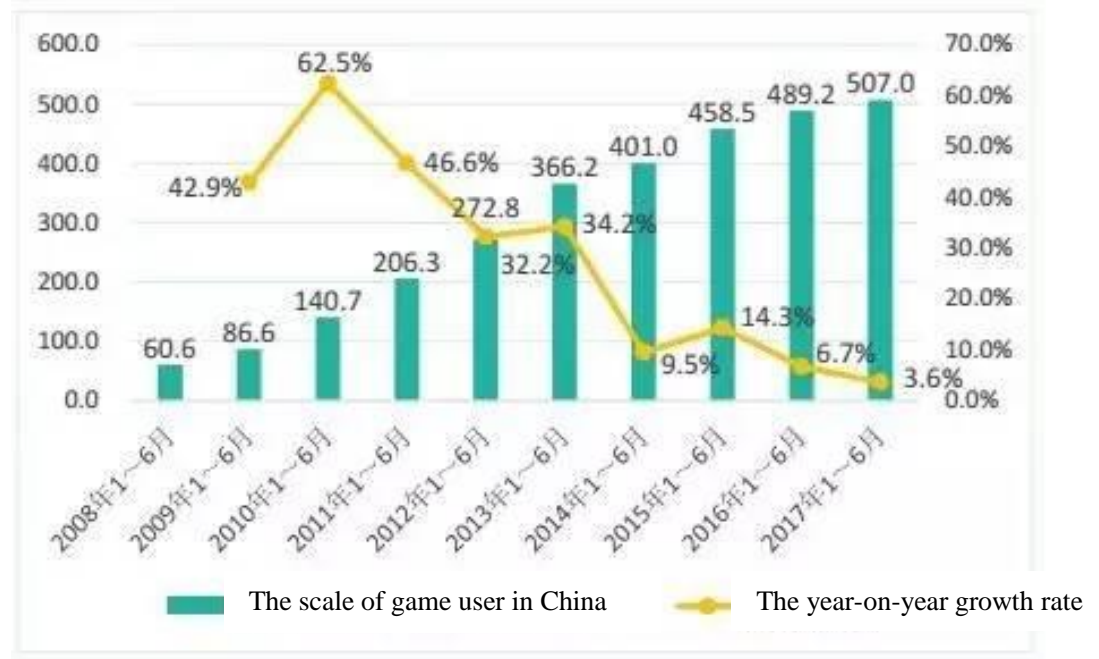

${ }^{\text {a. }}$ Source: Qilu network

Fig. 1. Current market of NetEase game.

In 2016, NetEase's mobile game "Onmyoji" achieved great achievements in the industry, and directly opened a new era of mobile games. Its success has made 2016 known as the "Onmyoji" era, and has also laid the groundbreaking status of NetEase's game in China.

In 2018, an initial investment of 1 billion yuan was spent to develop e-sports services. The export of some products has become a key strategy for NetEase's games to open overseas markets.

\section{New Media Communication Market of NetEase Games}

For NetEase games, the mastery of the new media market is multi-faceted and comprehensive. For the new media, NetEase has been devoting energy and capital since 2015. In 2015, NetEase Games launched a "game enthusiast" slogan and launched a promotional video titled "2015 Emotional Movie - Game Lovers" on YouTube, Youku, Tencent, iQiyi and other popular video sites. During the time, the number of clicks increased, and it also occupied a hot list on Weibo, which led to the forwarding of many NetEase game fans. This directly created the leading role of NetEase games in the field of new media. The promotion of NetEase games to new media makes new consumers have great interest in receiving the information about games from new media. Therefore, the promotion of NetEase games is now inseparable from the new media.

\section{ANALYSIS OF NEW MEDIA COMMUNICATION OF NetEAsE GAME}

In order to more directly and comprehensively understand the various data and strategies of new media communication of NetEase game, the following will analyze NetEase game new media from several dimensions. Due to the large number of games subordinate to NetEase games, the games chosen in the following analysis are suitable for the analysis of new media communication strategies as far as possible. Among them, the more successful new media communication cases of games in the NetEase game will be analyzed separately to find out the communication strategy to provide a reference for the communication of new media for other games.

\section{A. Audience Analysis}

The player is a very important part for a game company. He decides the direction of a game company and the development path afterwards. Therefore, it is necessary to first analyze the audience of the NetEase game.

1) Analysis of audience age: The age range of the audience determines the type of aggregated game within a company's phase, and whether it is necessary to adopt the audience with the most concentrated age group as the main recipient of communication. 


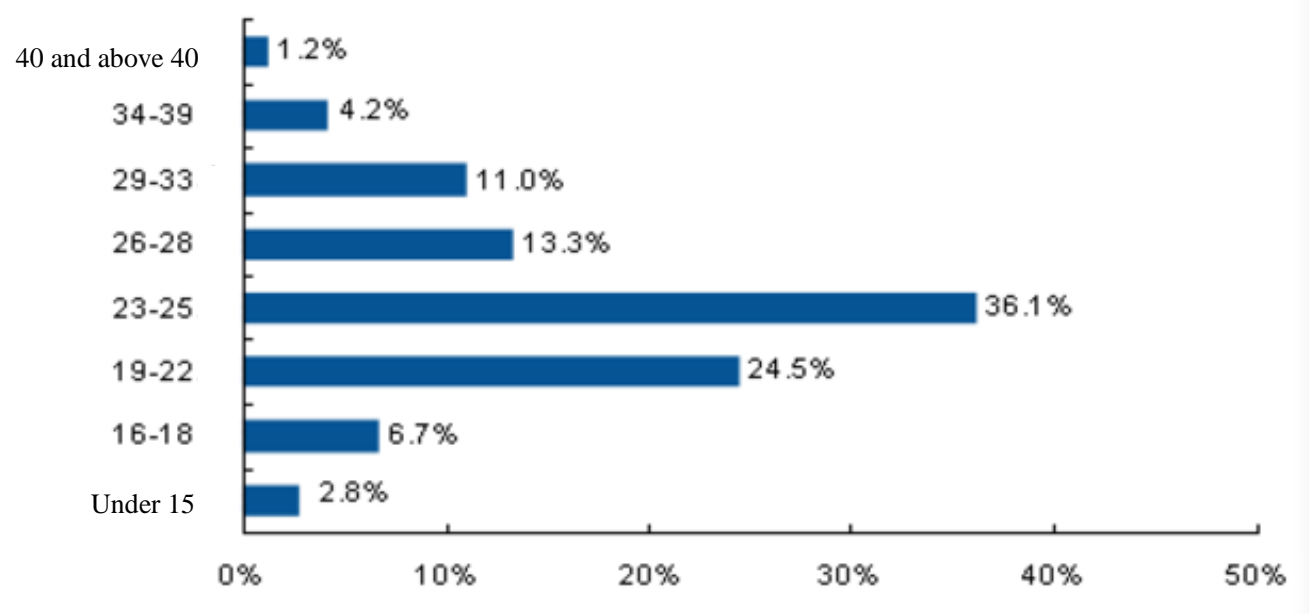

Fig. 2. Consumer survey of NetEase games.

According to the consumer survey of NetEase Games in "Fig. 2", 19 to 25-year-old users are the main force of the game, accounting for nearly $60.6 \%$ of the total users. The main feature of them is young, so they have a large amount of disposable time, and there is no pressure for family and work.

From the survey, the use of games by elder players can be improved, and number of users of 28 and above is nearly $16.4 \%$. With the penetration of the Internet into the lives of the elder players, there is a lot of room for the development of elder players who are generally linked to high investment ratio.

2) Analysis of audience career: The career classification of audiences is closely related to the income of the game, and it indirectly determines what kind of platform is used for communication of game.

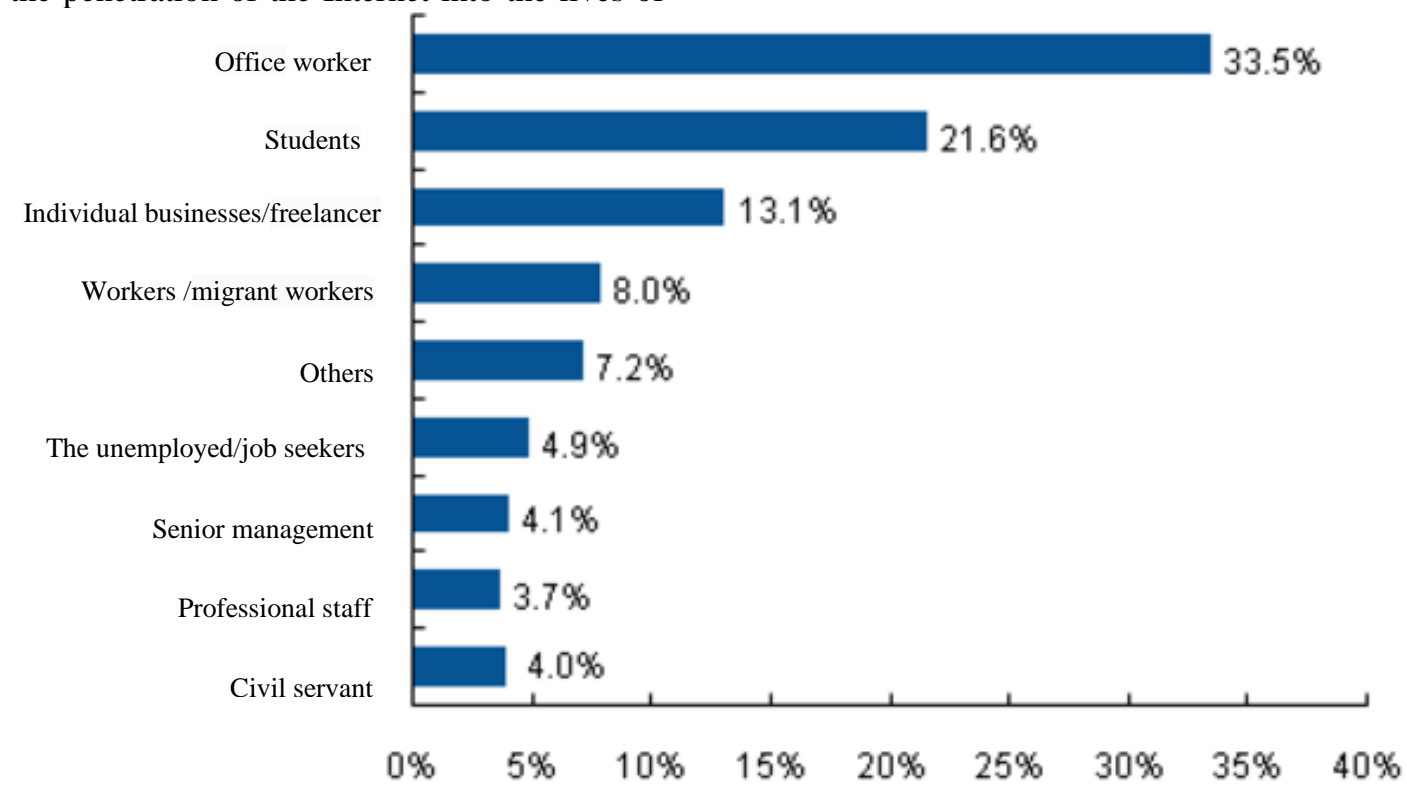

Fig. 3. The career classification of audiences.

Among NetEase games users, office workers account for nearly $33.5 \%$. The largest main users have more stable disposable income, which can be used for their own consumption in the game.

In addition, middle and high management personnel and self-employed persons account for $20.9 \%$, and these two types of users generally have high potential for consumption.
3) Analysis of the audience's choice of game: The popularity of the game also represents the trend of the game in the society, which can help game companies to plan their specific communication strategies based on the characteristics of their lively games. 


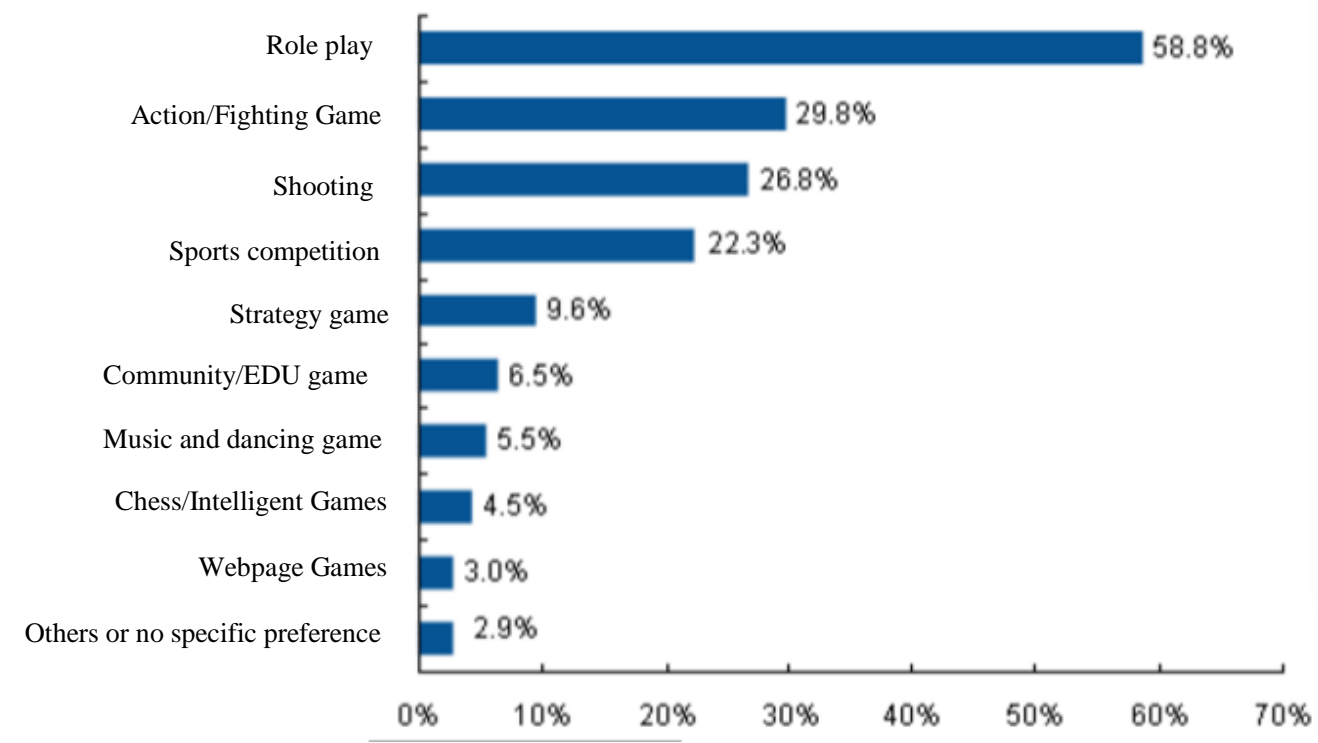

Fig. 4. The favorite type of most users of NetEase games.

In this era when mobile games are becoming popular, the popularity of computer games has been much worse than before. This survey is specifically targeted at mobile game categories. It can be seen that role-playing games are the favorite type of most users of NetEase games, with nearly $60 \%$ preference. In terms of the number and quality of heavy multi-people games such as SPG, action fighting and shooting games in 2017 to 2018, NetEase has had a good performance. The market share of 2018 is still stable.

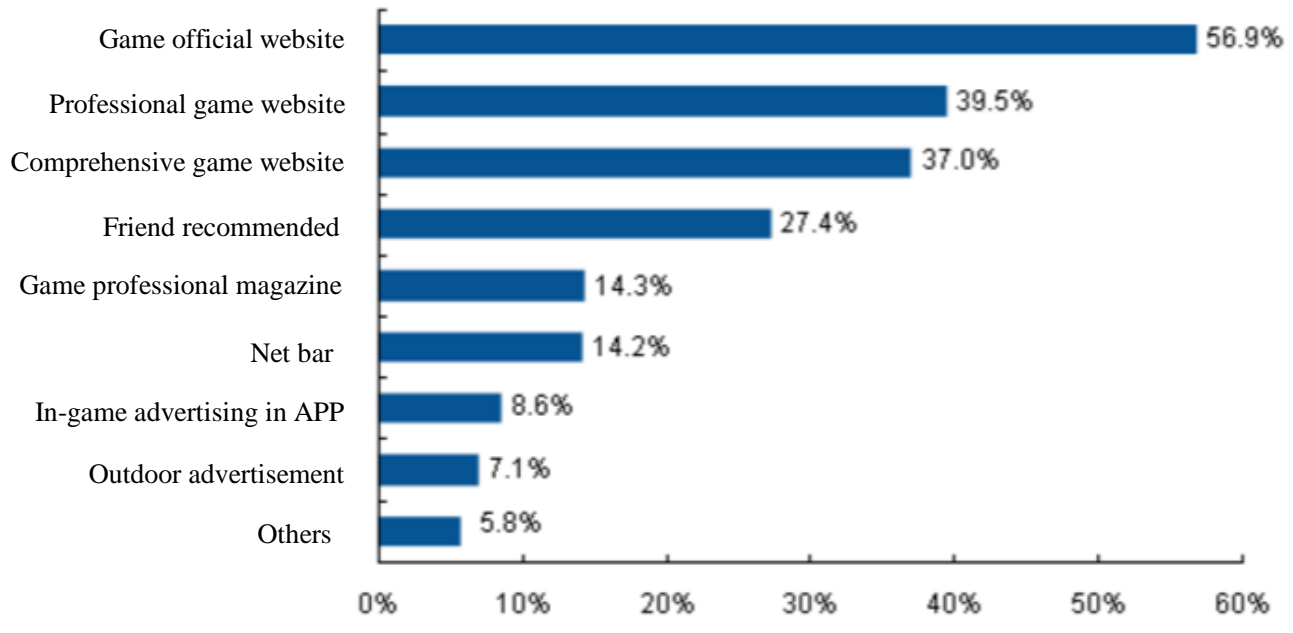

Fig. 5. The channels for audience to get information.

For game enthusiasts, information about the game is also basically taken from the Internet. $56.9 \%$ of them choose to receive information from the official website of NetEase. NetEase games have a specialized game site and the comprehensive data and neat classification is a model that many game companies imitate. The users who obtained data
4) The channels for audience to get information: This user survey is divided into two categories. One is the game enthusiast, which is equivalent to the game expert who loves NetEase games and has a great sense of loyalty. The other is the ordinary game users who are not obsessed in games but has a certain degree of loyalty to NetEase. from professional gaming websites and comprehensive websites account for $39.5 \%$ and $37 \%$, respectively in "Fig. 5".

Since they are professional game enthusiasts, their friend recommendation, internet cafes, and professional magazines all have some degree of information recognition, but these all belong to offline communication instead of new media. 


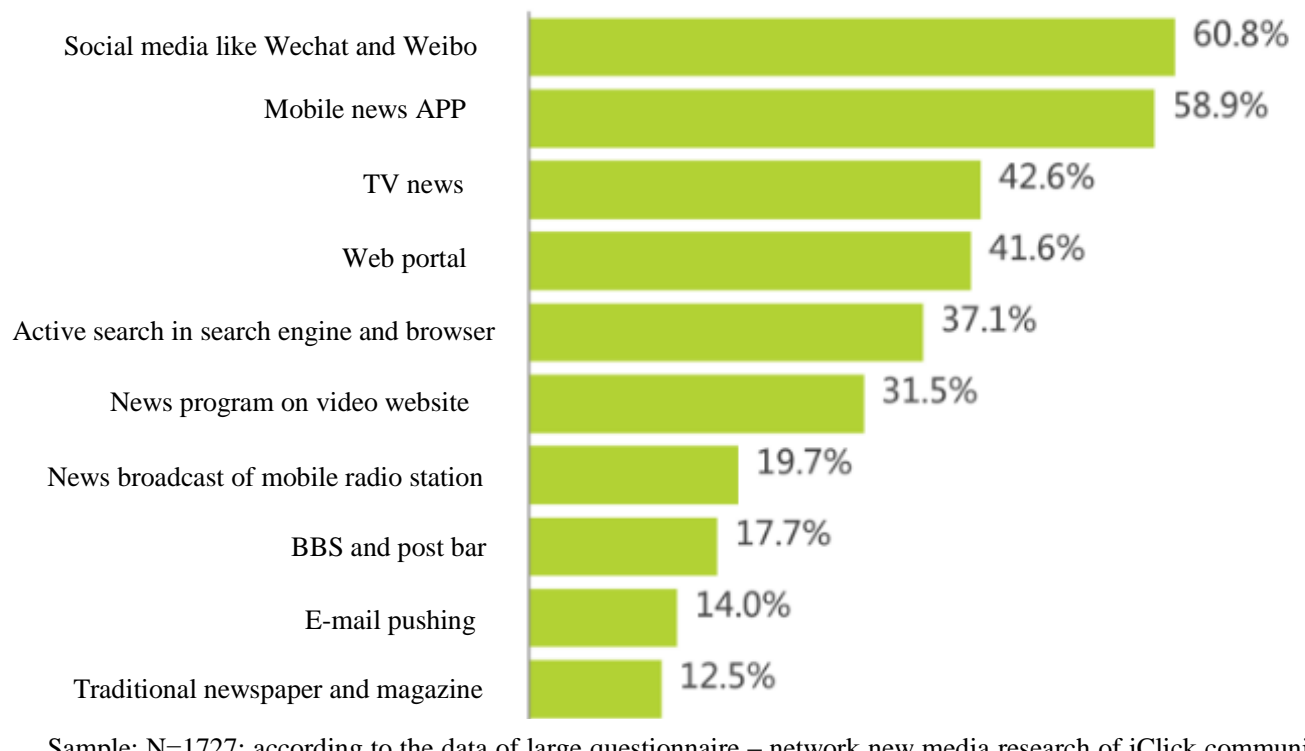

Sample: N=1727; according to the data of large questionnaire - network new media research of iClick community in Jan. to Mar. in 2016.

Fig. 6. The channels for audience to get information.

And $60.8 \%$ of other NetEase game users get game information through WeChat, Weibo or other social media as in "Fig. 6". The new media advertising investment of NetEase game is multi-faceted. Its figure can be seen in most of the hot new media software, and NetEase also presents at the advertising time of mobile news, television and movie. It can be said that NetEase games fully utilize the features of fragmentation, speed, interaction, and sea quantification of new media communications.

\section{B. Analysis of Communication Channel}

The new media communication channels of NetEase game are relatively various. Basically, the apps that are active in today's society and are more popular will be used, and it also involves some of the more niche new media software based on partial audiences. The purpose of this paper is to provide other games with basic references for the new media communication. Therefore, some more common new media software has been selected for analysis.

1) Weibo: NetEase Games opened its special Weibo account in 2010. Due to the constant development of new games and new derivative businesses, many related Weibo accounts have been opened for promotion. It makes the contents of the main accounts of NetEase games become less complicated and specializing in nature, such as reasonable customer service accounts, recruitment accounts, and publicity with high efficiency. This is in line with the principle of attaching importance to systemic layout in Weibo marketing. NetEase games incorporate Weibo into the overall corporate plan and give more play to Weibo.

From the above, we can see that the content of Weibo of NetEase game is mainly the game daily with promotion as aid, and it sets up more sub-accounts classified by games. The management layer between upper and lower Weibo accounts and the content are different, and the audience is also different. For the interaction of enterprise microblog, the publicity information cannot exceed $10 \%$ of the total. NetEase also does this well. It takes the daily titbits of games that fans are interested in as the main content of microblog.

The microblog of NetEase games, in order to win over young fan groups, cooperates with many big Internet celebrities to launch lucky draw or drive the promotion effect by other brands. It was proved that this action of NetEase game achieves its goal and is successful, so the microblogs of NetEase games both get a large number of fixed fans and realizes the interaction of Weibo and fans.

2) Official accounts: WeChat official account of NetEase was opened earlier and there were more activities on the official account, so it gained a lot of fans early on. The official account of NetEase game has also developed a small program of NetEase games, which brings daily welfare to players. It also does a very good job in the classification of games. Most NetEase game users will choose to use this small program.

The difference of WeChat from Weibo is it can push personalized articles that meet the needs. However, compared to Weibo, the development of WeChat new media is somewhat weak. In particular, the largest audience for NetEase games is students and office workers who have just entered the society. Therefore, in fragmented living situations, the occupancy ratio of Weibo is often higher than WeChat, and it seems to be more convenient for students and office workers to use Weibo. Especially for the era of rapid change of online games, Weibo has more extensive and rapid game publicity with high acceptance rates.

3) Major game sites: In addition to its website, NetEase games also cooperate with other large-scale game sites. 
There are two kinds of channels for advertisement. One is NetEase games actively cooperate with the websites to advertise. Another is the game sites spontaneously advertise their games because of the newly produced games.

NetEase has maintained a good relationship with the large game site 17173, ali213, and gamersky.

Although the major computer game market is now shrinking compared with the mobile games market and the use of mobile phones is now more extensive and convenient than that of computers, for a considerable number of game enthusiasts, it is commonplace to visit game site or game forum every day. The game information on the game website is the fastest and most complete. Once NetEase games release new trailers, they will publish the latest information of their games in these game websites, making the audience who loves the game see the information in the first time, and pass on the information first time. This type of audience makes the information of NetEase games professional.

4) Official website of NetEase game: The homepage of NetEase game has always been known as the leader in game pages. The categorization is clear and there are links to every game. Different themes are changed on the websites according to different festival. The most popular games and the latest events will be put on the homepage for easy browsing.

In addition to the web pages of game, NetEase Games also launched a forum open site for providing information and player discussions - NetEase play. It mainly pushes main information, game strategies, and other types of posts, rather than merely introduction to NetEase's games. Instead, it is an all-in-one game information platform for all kinds of games.

5) Live broadcast platform: NetEase Games itself also developed a live broadcast platform in 2016 that was specifically designed for its own games.

CC Live is a game entertainment live broadcast platform of NetEase Game, of which the predecessor was NetEase CC. In May 2016, NetEase CC was renamed CC Live. People can see game live broadcast and entertainment live broadcast on CC live broadcast platform and game live includes most of the popular games of NetEase games. The number of registered users of CC Live has now exceeded 100 million.

In addition to NetEase's own live broadcast software, NetEase games have popular games suitable for live broadcast. For example, "Knives Out" or "Terminator" is one of the types of game live broadcasts that users of live broadcast currently enjoy the most. Therefore, there are hosts live broadcasting these games on major live broadcast websites such as douyu.com, huya.com, or bilibili.com. When the host broadcast live games, there is a kind of crowd mentality. When the number of people watching a game is large, viewers will have a "crowd mentality". Even if they don't like this game, they will "download it following the trend", so that they won't appear out of fashion. Therefore, the benefits brought by the live broadcast to NetEase games are obvious. The live broadcast is a hot new media communication mode for modern young people. NetEase games firstly let the host and the live broadcast platform start the live broadcast to drive the warm-up of game at the beginning of the game and the gripping plot of the game and the competitive approach suitable for live broadcast platform also caught the hearts of a large group of young game lovers.

\section{Analysis of Communication Strategy}

The communication strategy of NetEase game is diversified, and it does not apply the same principles of modern warfare communication strategy to different games. Instead, it customizes the new media communications strategy according to the categories, attributes, and corresponding audiences of games. The new media communications strategy of NetEase game can now be divided into the following categories.

1) To stimulate nostalgia by combining with Chinese culture: Nostalgic marketing is a very common strategy in the communication. It generally allows the audience to generate certain nostalgic elements to stimulate his nostalgic feelings and directly evoke his buying tendencies. Many old brand names use this strategy for publicity, and it is also true for games.

The role-playing games produced by NetEase games are referred to as MMO games for short, most of which are Chinese antique games. Most scenes in the game restore ancient Chinese landscapes. Among them, "Chu Liuxiang", "A Chinese Ghost Story" and "Demon Seals" are taken as examples. In the promotion of new media, antique flavor is mainly taken as a selling point. In addition, traditional activities will be launched in the game on the traditional festivals in China.

For example, during the Spring Festival of 2018, the newly launched "Chu Liuxiang" pushed campaign joining the hand of intangible cultural heritage and formed a program on Weibo to become hot news, stimulating enthusiastic discussions between players and non-players.

This activity incorporates many Chinese folk New Year cultures in the game scene, such as lanterns, lion dances, paper cutting, and silk umbrellas, etc. Players can directly click on the web pages directly from the game that directly introduce the six Chinese intangible cultural heritages to player users, allowing players to integrate directly into the world of rivers and lakes to attract consistent praise.

In addition, the NetEase game "A Chinese Ghost Story" has obtained the copyright of Calabash Brothers when launching the new version, intriguing the online user's nostalgia, and the Chinese animation studio "Steam Workshop" launched the promotion mode of microfilm "A Chinese Ghost Story and Calabash Brothers Special". The entire story uses puppet fixed format animation in Chinese old animation period, so there is feelings and story line without seeming hypocritical. After the film comes out, it arouses repercussions immediately on Weib. Except for the large number of two dimension elements on Weibo, it also gains popularity in the bilibili.com and Acfun.com. "A Chinese Ghost Story" ushered in the second download boom after it opens service. 
Digging out nostalgic factors or creating factors in products is the key point of nostalgic marketing. Instead of simply adding a factor to the product blindly, it adds a factor that combines the two points of NetEase and game. Only by capturing the psychological feelings of the audience can we create the effect of nostalgia. It is also necessary to pay attention to the uniqueness and adaptability of NetEase game itself, grasp the degree and refuse to follow suit and copy.

NetEase games have spent a lot of energy in this aspect. It is generally based on Chinese antique games, and exquisite character modeling and antique game modeling have attracted large numbers of fans for the game. In the combination of the game and the Chinese culture, it has a superb experience, so it tries to show the most beautiful side of Chinese culture to the players, giving the player visual surprise. Starting with traditional festivals can also intrigue the remembrance of players for culture and curiosity about the unknown.

2) To expand consumer groups through drama implantation and celebrity endorsement: When the "A Chinese Ghost Story" was just put on the line in 2016, it became popular because of the advertisement implantation in the annual hot idol drama "A Smile Is Beautiful". This implantation brings obvious results that the registered user of the game increases straightly. The advertisements implantation in TV dramas is not a new way of communication, but the game layout in "A Chinese Ghost Story" is linked closely with the story line of the TV drama. The details are breathtaking and the marketing of the game has achieved a new level.

From this channel, it can be seen that there is a reason for NetEase games to invest a lot of money in this large-scale IP TV drama. First, this type of TV drama is inseparable with games. When talking about this TV drama, it is natural to think of the game promoted by NetEase. Second, the effect of the integration of drama and game plots is considerable, especially for such idol-like dramas where fans can integrate themselves into the role of television characters and the audience of the TV series is precisely the audience that NetEase game needs. This game is partial feminine, so it can bring large-scale female players to NetEase games.

In addition, in the eyes of contemporary audiences, celebrities' influence is quite high. It affects them directly and indirectly. It is also a widely used publicity method in recent years. Its ultimate purpose is to attract the attention of the audience, so that the audience's eyes can be extended to the products they represent, and the potential of fans can be stimulated.

In the middle of 2017, when the appointment with Yang Yang, the spokesperson expired, they signed the next spokesperson $\mathrm{Hu}$ Yitian. And in the beginning of February 2018, the game's micro-movie "Someday" was released, and a new wave of popularity is picked up relying on the new spokesperson.

Next, the rules of choosing endorsement stars of each NetEase game are also visible, such as Yang Yang, Hu Ge, Lin Xin, and Liu Shishi and so on. First of all, the spokesperson chosen by NetEase game is definitely a popular star with a hot IP at the time. Hu Ge's signed a contract for NetEase games immediately after the launch of "Nirvana in Fire". The stars all have classic costume characters to be in line with the image of Chinese style game of NetEase game. In addition, the signed stars have more or less contact with the game in life, or like playing games.

3) To add hotspots to meet consumer needs: Responding to hot spots is actually another kind of "borrowing opportunities" for marketing, which integrates products into an environment that adapts to the times, quickly attracts the interest of the audience, and can be pleasantly and easily accepted.

The chasing footstep for hotspots of NetEase game is fairly advanced. When Playerunknown's Battlegrounds rising in 2017 began to get popularity in China, NetEase games expresses that the game will officially launch recently in a variety of new media software immediately, which brings numerous fans and the popularity of the two games "Terminator 2" and "Knives Out" soared.

Later, in order to maintain the heat, NetEase games continuously released activities related to social hot topics, and make connected activities with KFC and OFO have. The effect is not plain.

It implants the yellow car into the game. At the time of summer, the heat of OFO was quite high. After the players got the news, they downloaded the game with the sense of freshness, which caused a hot debate on the Internet.

Through analysis, brand hotspots launched by NetEase games are generally the brands that are popular among young people groups or those that were quite popular in the previous period. The activities launched are also related to the lives of young people, or are event planning made especially for a certain young community such as the two dimension community. The hotspot spread of NetEase games win the eye of the audience mainly through the media and promote its communication market in relaxed and entertained way with the help of the audience's own capture and promotion of hotspots.

4) Multicultural integration of overseas agent: In addition to the independent research and development of games in recent years, NetEase games have a partnership with game companies in many countries. In order to better fit the Japanese and Korean games, in addition to opening booking platforms in major gaming websites, it also forms a dual-agent game platform strategy with bilibili.com, and opens an appointment platform in bilibili.com. The booking platform for the Fifth Personality has been open for only two months, and the number of appointments has exceeded 2 million.

In addition, in order to make foreign games more acceptable, NetEase games makes multi-cultural improvements to the games when the games are introduced to China to make them more in line with Chinese aesthetic characteristics. The current hot game "eternal 7-day capital" combines both Chinese culture and Japanese culture. It also 
carried out activities during the Spring Festival and received good results in the new media.

The success of NetEase games in the field of communication in recent years has led to a gradual expansion of its agency road, and it cooperates with agents and game companies in various countries. With the growing popularity of NetEase's games in foreign countries, foreign game companies also prefer its communication form to increase its popularity, so they are willing to use NetEase games as the agent. And in the market with numerous types of games, NetEase game also constantly broadens its game library to broaden its game market audience with comprehensive game development.

\section{Summary of Communication Effects}

The game is now an entertainment product belonging to young groups and even children for the majority of people in the society. With the development of the game, NetEase launched a series of fast-paced games for young social groups and won the favor of young people. And for its advertising, NetEase games adhere to grasp the preferences of young groups and make moderate planted advertisement in the popular new media software. With the innovative advertising model, NetEase games are now the best choice for young gamers.

In addition, the popularity and communication efforts of NetEase game make the launch of each game of NetEase games accompanied by high hotspots and high attention. The download of "Onmyoji" and "Chu Liuxiang" all exceeds one million on the first day. In the later stability and recession period of game, NetEase games adds the later new media communication strategy to trigger large-scale influence, making the game increase the download amount during the medium period.

Since the reform of the communication of NetEase games in 2015, the web influence of the Internet has been the cutting-edge of Chinese game companies. The number of registered players of NetEase game direct live broadcasting platform has exceeded 100 million, and the number of followers of Weibo's main account is 260,000 . However, the number followers of each game account have exceeded 1 million and the number of appointments reaches 2 million on the first two months since the opening of new game booking platform of NetEase game. The cooperation channels of NetEase's overseas agents increase with the company's popularity. This also has directly expanded the overseas market of NetEase games. NetEase Games has been partner with Blizzard Entertainment since the early years and nine out of ten of the games introduced are produced by Blizzard Entertainment. These NetEase games have a place in the game market in Asia with the changes in various types of games and the increase in popularity of its brands. In addition to cooperation with Blizzard Entertainment, the introduction of Japanese and South Korean game in 2018 will also be further discussed.

\section{DEFICIENCIES AND SUgGeSTIONS IN THE NEW MEdia COMMUNiCATION OF NetEASE GAME}

\section{A. Deficiencies}

1) Limit of audience age: The size of players group of NetEase game is slowly expanding, but the age group of the audience is still generally young. This is not only because of the type of game, but also because most of the new media platforms involved in the new media communication are used by young people. It is difficult for social elite to access the advertisement of NetEase game.

2) Unconformity between advertising communication and game themes: The game should match the corresponding new media communication mode. Developing a good new media communication environment is not suitable for all NetEase games. Taking Onmyoji as an example, when Onmyoji was popular in early days, the new media communication is not much because the uniqueness and topicality of the game can occupy the game list for a long time. In the end of 2017 and early 2018, Onmyoji has already experienced a downward trend. At this time, the new media communication selected by NetEase games is to play advertisements in movie theaters.

This step is very unwise. First of all, the topicality of "Onmyoji" has passed. Now the advertisement has no influence, and it may cause the illusion that the game has passed. Secondly, Onmyoji as a game, NetEase games did not make a formal advertisement for it, so it was rather thin on the screen of a movie theater. It was just as if it was cut off from the screen of a mobile phone.

3) Visual fatigue caused by single communication of games: The current new media communication of NetEase game is similar. There isn't any good idea and hotspot but the interval is too long, and not every game can have an outbreak of innovative communication. New media platform advertisements such as Weibo and WeChat may cause aesthetic fatigue and rebellious psychology since players and users have been exposed too much.

4) Fierce competition between the live broadcast platforms: The most popular game live broadcasts of NetEase games are "The Terminator" and "Knives Out". These two games are very popular on the major live broadcast platforms in 2017. However, with the launch of two types of mobile games "PlayerUnknown's Battlegrounds" with copyright by Tencent at the beginning of 2018, the downloads and live streaming numbers of NetEase game have declined. Players' preference for watching live broadcasts is also Tencent's games. Many hosts who cooperated with NetEase games were also invited by Tencent to live broadcast "PlayerUnknown's Battlegrounds" because of the expiry of the contract in 2018. This directly led to a straight decline in the amount of live streaming of NetEase games in early 2018.

5) Promotion period of proxy game is too long: NetEase games will issue an announcement for agenting the game 
after the agency, and related game backgrounds will be announced on the official website and other game websites. However, due to the consultation, revision, and copyright of the game, and developing agents after the agency, it takes too much time from taking over the game to the launch of the game. In addition, some accidents that may occur during the development of the game dissatisfy the users who are waiting for the game. Taking "The Fifth Personality" as an example, there is no reason and the indication for the sudden shut of the test server and no notice is given, which makes the player complain about it. After that, "Fifth Personality" published a letter of apology on various new media platforms.

\section{B. Suggestions and Improvements}

1) The development and publicity should conform to social elite: In addition to the promotion in the new media software or platforms used by young people, NetEase games should also cater to most social workers. For this group of people, the game is a good way to vent and decompress. NetEase can seek cooperation opportunities in the news or magazine APP to increase the opportunity for the social workers to know NetEase games. It can also cooperate with the major official accounts to send tweets about NetEase games.

2) Rational use of innovative advertising implantation model: The success of TV advertisement implantation in "A Chinese Ghost Story" has made NetEase games have a lot of investment in the implantation of game ads. In the recent game ad placement, the most successful one should be "Chu Liuxiang" in cooperation with Tik Tok. As a short video social APP, Tik Tok let users to watch the recommended videos on the homepage by scrolling up and down. NetEase games upload videos of wonderful characters and scenes in the game here to attract users' attention. A considerable number of players of Chu Liuxiang also upload funny videos in the game to Tik Tok. This communication method of NetEase game spreads the game and it is very suitable for this app. Therefore, the game has gained a lot of attention.

3) New media communication needs features: NetEase games should open up more innovative ways of communication, and can use a combination of new media as the mainstay and offline interaction as a supplement to conduct the communication of a series of games. Taking "Terminator" as an example, after a player dies in a game, it will become a box with props, so NetEase games can use this as a prototype to launch a series of game related boxes and place game related products randomly in the box. Then it advertises on Weibo to send the "boxes" to the top 10 in the game, and 10 Weibo users who forward the lottery tweet, or contacts the game host to make the live braodcast of opening the box, so that the focus and interest of game will rise. This activity has a certain reward mechanism that inspires players' desire to play.
NetEase games should pay more attention to online and offline new media communication methods to explore communication models that are popular among consumers based on the positioning of their own game brands.

4) Live broadcast platform should create innovative models: In 2018, NetEase Games has already indicated that it will directly promote live broadcast to a strategic business, thereby forming a live broadcast ecosystem for NetEase. In addition, while supporting the live broadcast industry, NetEase games will also join the e-sports industry, making live broadcast and e-sports coexist.

This action undoubtedly adds to the NetEase game and makes live broadcast platform of NetEase game more appreciable and interesting, so as to restore the decreasing users of live broadcast circle.

5) Communication cycle of Agent game should be adjusted and optimized: After NetEase Games accepts agent games again, it can appropriately release messages instead of making publicity greatly. It can start promotion on the new media platform two months before the game is ready to go public. However, during the promotion process, blindly promoting or releasing only the introductions and information of games is rather boring. Therefore, it can carry out some small games similar to quiz or lottery on the Internet combining with agent games. It is also possible to open part of the trial version of the game to increase the player's expectations and the interest of general audience.

\section{CONCLUSION}

In short, as one of the two giants in China's game industry, NetEase games can be said to have been at the forefront of online game companies in the use of new media and promotion. Although there are still some deficiencies, it does not obscure the virtues. The new media communication of NetEase game is still a strong reference for the new media communication of other domestic Internet game companies. At the same time, with the continuous updating and optimization of new media technologies, it is believed that in the future, online games will become an indispensable part of the entertainment life of the general public, and the popularity and recognition of NetEase games needs to be further strengthened and consolidated. Therefore, how to face the new challenges and new trends in the new media environment in the future and realize the efficiency and effectiveness of the communication will be the issues that NetEase games need to continue to pay attention to and face.

\section{REFERENCES}

[1] Fu Yuhui. An Overview of China's New Media Communication Research in 2015 [J]. Journal of International Communication, 2016. 付玉辉. 2015 年中国新媒体传播研究综述[J].国际新闻界, 2016

[2] Xu Yimam. Analysis of the Development Trend of New Media Communication [J]. Journalism \& Communication, 2014. 徐溢蔓. 新 媒体传播的发展趋势分析[J].新闻传播, 2014

[3] Shang Lingbo. Analysis of New Media Communication Law under Internet Thinking[J]. New Media Research, 2017. 尚凌博. 互联网思 维下的新媒体传播规律探析 $[\mathrm{J}]$.新媒体研究, 2017 
[4] "Onmyoji" Powerfully Assists NetEase Games to Record Revenue in the Fourth Quarter of Last Year. [J]. Business Culture, 2017. 《阴阳 师》强力助攻网易游戏去年四季度收入创历史新高 [J]. 商业文 化, 2017

[5] Liu Sisi. Research on the Characteristics of Interpersonal Communication of Online Games and Its Influence on the Interpersonal Interaction of Young Players[J].Guangxi University, 2017. 刘思思.网络游戏的人际传播特征及对青年玩家人际交往的 影响研究[J].广西大学, 2017

[6] Ma Yue. Analysis of the Development Trend of Advertising Implantation in New Media Environment [J]. New Media Research, 2017. 马悦. 新媒体环境下广告植入的发展趋势分析[J]. 新媒体研 究, 2017.

[7] Guo Qingguang. Communication Course [M]. China Renmin University Press, 2011,66. 郭庆光.传播学教程[M]. 中国人民大学出 版社, 2011，66.

[8] Qian Yalei. A case study of the marketing strategy for NetEase's mobile online game "A Chinese Ghost Story" $[\mathrm{J}]$ Wuhan Textile University, 2016. 钱亚蕾. 网易公司手机网络游戏《倩女幽魂》市 场营销策略案例研究 [J], 武汉纺织大学, 2016

[9] Sun Jiashan. From online games to online literature and art [J]. Red Flag Abstracts, 2017. 孙佳山. 从网络游戏到网络文艺[J]. 红旗文 摘, 2017

[10] Yu Mingyang, Shu Yongping. On "Brand Communication" [D]. School of Journalism and Communication, Huazhong University of Science and Technology. Wuhan, 2002. 余明阳、舒咏平. 论 “品牌 传播” [D].华中科技大学新闻与传播学院.武汉, 2002

[11] Zheng Guoqiang, Liu Lu, Yang Xiaozhu. The great influence of new media technology on advertising [J]. Art Science, 2017. 郑国强、刘 露、杨小竹. 新媒体技术给广告带来的巨大影响 [J]. 艺术科 学, 2017

[12] Shi Mengiiao. Analysis of the status quo and development prospects of China's online game industry from products of NetEase [J]. The Fortune Times, 2012. 石梦娇. 从网易旗下产品分析中国网游产业现 状及发展前景[J].致富时代, 2012

[13] Jin Ming. Research on the structure dimension, influencing factors and the mechanism of brand loyalty for brand favorite [D]. Zhejiang University, 2011. 金明.品牌钟爱结构维度、影响因素及其对品牌 忠诚的作用机制研究[D].浙江大学, 2011

[14] Chen Zhe. Analysis of the regularity of science communication in the era of new media [J], Dalian University of Technology, 2009. 陈哲. 新媒体时代科学传播规律性探析 $[\mathrm{J}]$, 大连理工大学, 2009

[15] Yang Jing. Research on the Characteristics of New Media Communication [J] Henan University, 2009. 杨静. 新媒体传播特征 研究 [J], 河南大学, 2009

[16] Huang Jian. The basic status quo and development trend of new media communication industry under the background of Internet age [J]. Coastal Enterprises and Science \& Technology, 2009. 黄健. 网络 时代背景下新媒体传播业的基本现状和发展趋势 [J]. 沿海企业与 科技, 2009 . 